\title{
BARRIERS TO A BETTER BRISTOL: DIAGNOSING CITY STRATEGIC SUSTAINABILITY CHALLENGES USING SYSTEMS, CO-PRODUCTION AND INTERDISCIPLINARY APPROACHES
}

\author{
EMILY PRESTWOOD ${ }^{1}$, THOMAS CALVERT ${ }^{1}$, WILLIAM CLAYTON ${ }^{1}$, JAMES LONGHURST $^{1}$, \\ HELEN MANCHESTER ${ }^{2}$, GRAHAM PARKHURST ${ }^{2}$, GES ROSENBERG $^{3}$, \\ COLIN TAYLOR ${ }^{3} \&$ IAN TOWNSEND 4 \\ ${ }^{1}$ The Faculty of Environment and Technology, University of the West of England, UK \\ ${ }^{2}$ Graduate School of Education, University of Bristol, UK \\ ${ }^{3}$ Faculty of Engineering, University of Bristol, UK \\ ${ }^{4}$ The Bristol Green Capital Partnership CIC, UK
}

\begin{abstract}
As European Green Capital 2015 and one of the Rockefeller 100 Resilient Cities, Bristol can legitimately claim to be on the "frontline" of urban sustainability, continually challenging itself to transform into a place where citizens and organisations work together to create wellbeing. Yet the development pathway to achieving this transformation, remains characterised by continuing inequalities in social inclusion, health outcomes and access to transport, despite aspirational goals envisioned by the city's leaders. The Urban ID (Integrated Diagnostic) project aims to address this, with the intention that the approach will be replicable in different contexts to assist in developing policy strategies at all levels. The project partnership of local authorities, partnerships, businesses, citizens, and universities is creating a "diagnostic approach" to identify and address the challenges and barriers faced in achieving a strategic sustainability vision. The diagnostic approach is being developed through participatory research using systems, co-creation and learning approaches between a diverse range of stakeholders, in combination with the examination of relevant information including city data, expert opinion, and policy documents. A common shortcoming of projects addressing sustainability in a holistic way is that individual issues are investigated without consideration of the interdependencies between them and with a 'business-as-usual' mindset. To address these shortcomings, Urban ID focusses on several local case studies as well as a city-wide sustainability community case study. These are examined through the 'lenses' of mobility and accessibility, carbon neutrality, health and happiness, and equality and inclusion. As a result, all issues in a case study area are examined, to better understand the links between them. This paper provides an overview of the Urban ID concept and development of the diagnostic approach, and reports the initial findings and outcomes from a first-round of engagement activities in the Bristol Green Capital Partnership (BGCP) sustainability community case study, co-produced with BGCP CIC.
\end{abstract}

Keywords: sustainability, systems, co-production, carbon neutral, mobility, accessibility, health, happiness, inclusion.

\section{INTRODUCTION}

Bristol has set out to transform itself by 2065 into a vibrant place that empowers and enables its citizens to 'flourish', and creates long-term wellbeing in a sustainable and equitable way [1]. To support this aim, the city has developed international collaborations, city-wide partnerships and stakeholder engagement programmes which place it at the 'frontline' in terms of creative strategies to achieve urban sustainability. Bristol is prominent in 'best place to live' tables [2], has a vibrant and creative arts and cultural scene and has the lowest unemployment claimant rate of the UK's core cities [3]. However, despite progress towards ambitious development plans, challenges persist, particularly in terms of how equitably 
sustainability benefits are distributed throughout the urban area. Further investigation of the continuing barriers to inclusive sustainable development and a better Bristol is needed.

The Urban Integrated Diagnostics (Urban ID) project, funded by all seven of the UK Research Councils and Innovate UK, commenced in June 2016 and will be completed in November 2017. The project's aim is to develop a framework for diagnosing the barriers to transformation to a better, more sustainable Bristol. The diagnostic framework brings together systems thinking, learning, co-production and participatory approaches [4]-[6], integrating methods to develop a set of tools to understand the current situation in the city and the challenges and barriers present. This approach examines available information, including technical and policy documents, and data, focussing on four challenge themes, combining with evidence of the lived experience of citizens and organisations as co-produced knowledge. The project is testing the effectiveness of different tools to diagnose strategic sustainability challenges in five case study areas.

The first part of this paper provides an overview of the Urban ID project, describing the concept, strategic sustainability challenge themes and research methods integrated in a diagnostic framework and exploratory case studies. The second section focusses on one particular case study, the Bristol Green Capital Partnership (BGCP) 'sustainability community', and describes the research design for the case study (co-produced with BGCP CIC) and presents findings from the first Urban ID workshop with partnership members.

\section{BACKGROUND}

\subsection{The Bristol urban area}

\subsubsection{Diverse and thriving but with continuing inequalities}

The Bristol urban area is diverse, economically developed and in many ways thriving, but is, nevertheless, facing a number of challenges to how the area transforms to one where everybody flourishes [1]. Social and physical mobility around the city are key concerns. Inequality between rich and the poor is pervasive and widening; adjacent city wards experience a 9.5 year life expectancy gap, with a difference of 25 years lived in good health [7]; and there is a significant lack of inclusion and diversity in decision-making.

The Bristol City Council Resilience Strategy [1], identifies and categorises these challenges as relating to "People", "Places", "Organisations", "Prosperity and Worth", and "Regional to Global". There are diverse communities in Bristol but cohesion is threatened by inequalities between people in the same and different areas. Though actions to 'green' the built environment have been successful, places are not transformed. Civil society is engaged but organisations are not yet fully connected. The city is economically successful but not all areas are equally flourishing. Strengthening local, regional self-sufficiency is key to resilience, but the city is still dependent on national and global systems.

The scale of many of these challenges and the fact that despite significant action in the Bristol urban area, problems persist suggest that business as usual (BAU) approaches need to be challenged. What is stopping Bristol from bridging the gap between its current situation and the desired future as encapsulated by the city's various visions and aspirations? How do we break down the barriers that sustain a collective, business-as-usual mindset? These are problems the Urban ID project is seeking to diagnose, examining how policy-makers can work with citizens and organisations (such as BGCP) to help communities conceive and realise disruptive solutions and deliver the large step changes needed. 


\subsubsection{Geographic area and boundaries}

The nominal geographic remit of the Urban ID project is the Bristol urban area, which approximately comprises the boundary of Bristol City and a significant proportion of South Gloucestershire Unitary Authority. The population of the Bristol urban area is approximately 620,000 , in the 2011 Census [8]. A meaningful concept of a "boundary" or "boundaries" in the Urban ID project is likely to be an emergent property of the research, as opposed to an imposed geographic extent. It will be partly defined by the activities of the project partners, and the organisations and citizens engaged and consulted through exploratory case studies, and partly defined by the data that is available.

\subsection{Urban ID concept: an integrated diagnostic tool}

The Urban ID project is a partnership project involving universities, local authorities (Bristol City Council and South Gloucestershire Council), local partnerships (Bristol Green Capital Partnership, Bristol Cultural Development Partnership, Local Enterprise Partnership and Bristol Health Partners) and many other organisations (Arup, Knowle West Media Centre, Buro Happold, Business West, Future Cities Catapult, Price Waterhouse Coopers, Royal Society for Arts, Watershed Media Centre and West of England Local Enterprise Partnership). The aim of the partnership approach is to dissolve silos for a truly cross-sectoral collaboration. Therefore, on the project, financial resources are shared between universities and external partners and partners are participants in research resign. The project also draws on internationally leading research in the Bristol area such as 'Bristol is Open', the ongoing Horizon 2020 Replicate project and co-produced and co-designed research projects such as Productive Margins.

At the heart of the Urban ID approach is co-creation and co-production, and an acknowledgement that citizen behaviour and action are essential to the delivery of desired societal outcomes such as equality, health, learning, and carbon neutrality. The project's aim is to synthesise existing domain-specific diagnostic methodologies and tools to create a novel integrated diagnostics framework, which will allow multiple viewpoints to be integrated and ensure the diagnosis of urban challenges does not become fragmented. The framework will be applied to diagnosis complex problems across four 'challenge themes': mobility and accessibility, health and happiness, equality and inclusion and the 'carbon neutral city'. Joint 'theme leaders' who are all 'end users' of the diagnostics are also participating with academic partners in investigations, ensuring research is interdisciplinary, cross-sectoral and grounded in real world application (Section 4 of this paper describes the role of BGCP as participants in co-produced research). The legacy of the project will be threefold: innovation in the diagnostic framework and methods needed to address urban challenges; application to the Bristol urban area and a diagnostics synthesis across the four challenge themes; formation of an evolving cadre of cross-sector city leaders with the capability to apply integrated diagnostics and challenge the prevailing 'business as usual' approaches.

\subsection{Challenge themes}

The Urban ID project has four challenge theme areas, with the barriers, challenges and solutions in each theme dependent and interdependent on the other themes; the diagnostic framework will be piloted in case study areas and barriers examined through the lens of these themes, allowing for a thematic analysis across the project. 


\subsubsection{The carbon neutral city}

A carbon neutral Bristol by 2065 is a top-level goal and aspiration of Bristol City Council, but what does carbon neutrality mean in the context of the Bristol urban area? Is the vision one of endogenous energy production meeting the city region's energy requirements for homes, businesses, transport and industry, or is it a broader, also encompassing the carbon emissions embodied in the goods and services we consume? To determine potential pathways and barriers to a carbon neutral city, it is necessary to determine which emissions are included in the definition and a vision of a future carbon neutral city is dependent on the spatial as well as temporal boundaries chosen. Therefore, for the carbon neutrality themes, defining the boundaries of the Bristol urban area's carbon emissions will be an important outcome of the project. Exploration of the relationships and interdependencies with the different challenge themes in the Urban ID project will diagnose barriers and opportunities along the route to this vision, across challenge themes, some well known but others arising through application of the integrated diagnostic framework.

\subsubsection{Health and happiness}

Assessing health and happiness as critical measures of societal wellbeing is becoming more accepted globally. Places cannot be seen as 'successful' if their inhabitants are not healthy and happy. Within cities, economic and environmental performance are very important, but they need to be understood within the context of human health and happiness. The Urban ID project conceptualises the key challenges to health and happiness in the city of Bristol. Most people want to see Bristol as a place where individuals and communities 'flourish', and yet the city faces key inequalities in health and happiness, related to poor accessibility, income, life chances and environmental quality. The Urban ID project is attempting to improve understanding of what stops Bristol from bridging the gap between the desire, by policy makers, other stakeholders and communities, to see a healthy, happy population and the reality of inequalities now and in the future. The project will challenge the mental model, which sees the city as serving the economy, rather than a city served by its economy, and will examine the interdependencies with other themes, particularly inclusion and equality.

\subsubsection{Mobility and accessibility}

Examining the barriers and challenges to a better transport system in the Bristol urban area would be meaningless without also considering the impact on accessibility. Currently, society and the built environment emphasises the car as the key transport system leading to over-dependence on car travel, which contributes to social exclusion, which has negative consequences on health and wellbeing such as poor air quality and is a barrier to moving to a carbon neutral city by 2065 . However, whilst many citizens and organisations can be described as over-mobile, some groups are insufficiently mobile to participate fully in society. In addition, the region is failing to meet air quality standards, with the transport system the main source of pollutants due to both the number of cars and the number of high emissions vehicles. Transport was a key public sector motivation for devolution (the West of England Combined Authority was established in February 2017). The area's challenges in ensuring an equally accessible and green transport system that positively contributes to a healthy and flourishing city region will be diagnosed and explored on the Urban ID project.

\subsubsection{Inclusion and equality}

The final Urban ID challenge theme; inclusion and equality, is concerned with the inclusiveness of the city and its organisations, and with how different communities can be equally represented in socio-economic decision-making, both private and public sector, and 
policy. This paper has described the paradox between Bristol's positions as an economically developed city on the one hand, with massive inequalities in and between different communities in the region on the other hand. If the city's health, transport, and energy systems and built environment are to be safe, accessible and green, and if everyone in the city is to experience wellbeing for the city to flourish, then the inclusion of citizens at different stages of decision-making is vital. For this reason, the inclusion and equality theme can be considered to envelop all the other three challenge themes, as well as being integral to the co-creation and co-production research methods that are at the heart of the Urban ID (integrated diagnostic) approach. If the city is to develop and flourish sustainably then it must do so inclusively.

\section{METHOD}

\subsection{Research design: exploratory case studies}

The Urban ID diagnostic framework will be piloted across five exploratory case studies in the Bristol urban area. The five case studies areas are: East Bristol and the Bristol/Bath Railway Path; BS4/Knowle West Community Led Housing Project; Metrobus; Staple Hill; the Bristol Green Capital Partnership 'Sustainability Community'. The geographic coverage of these case study areas is shown in Fig. 1 below. The East Bristol, BS4 and Staple Hill case studies are discreet areas in the city; whereas the boundaries of the Metrobus and BGCP sustainability community case studies are less distinct. As with the challenge theme areas, the carbon neutral city in particular, determining the boundaries of these two case studies will be an outcome of the research. For the Metrobus route the 'accessible' distance to stops $(1000 \mathrm{~m})$ is also marked in red.

\subsection{Research design: diagnostic framework}

The main aim of the Urban ID project is to develop and test a diagnostic framework of research activities and tools, which can be used to diagnose the Bristol urban area's sustainability challenges. The framework should allow for a core data set to be built, which will enable a comparison between the five pilot case studies discussed and will also allow for an analysis across all four challenge themes. To ensure data from different case studies is comparable a set of core data collection methods have been agreed. These core methods are as follows:

1. Draw on appropriate existing data, identifying missing data and sources.

2. Conduct an interdependency mapping exercise and document the outcomes.

3. Use at least one participatory/creative approach and document the outcomes.

4. Conduct narrative interviews with a range of different actors associated with the case study.

5. To complete learning profiles matched to the interviews, where possible.

In addition to a common core data set, each case study may do bespoke enquiries, exploring other methods as appropriate to the challenges of each case study area and the requirements of the non-academic project partners co-leading case studies. 


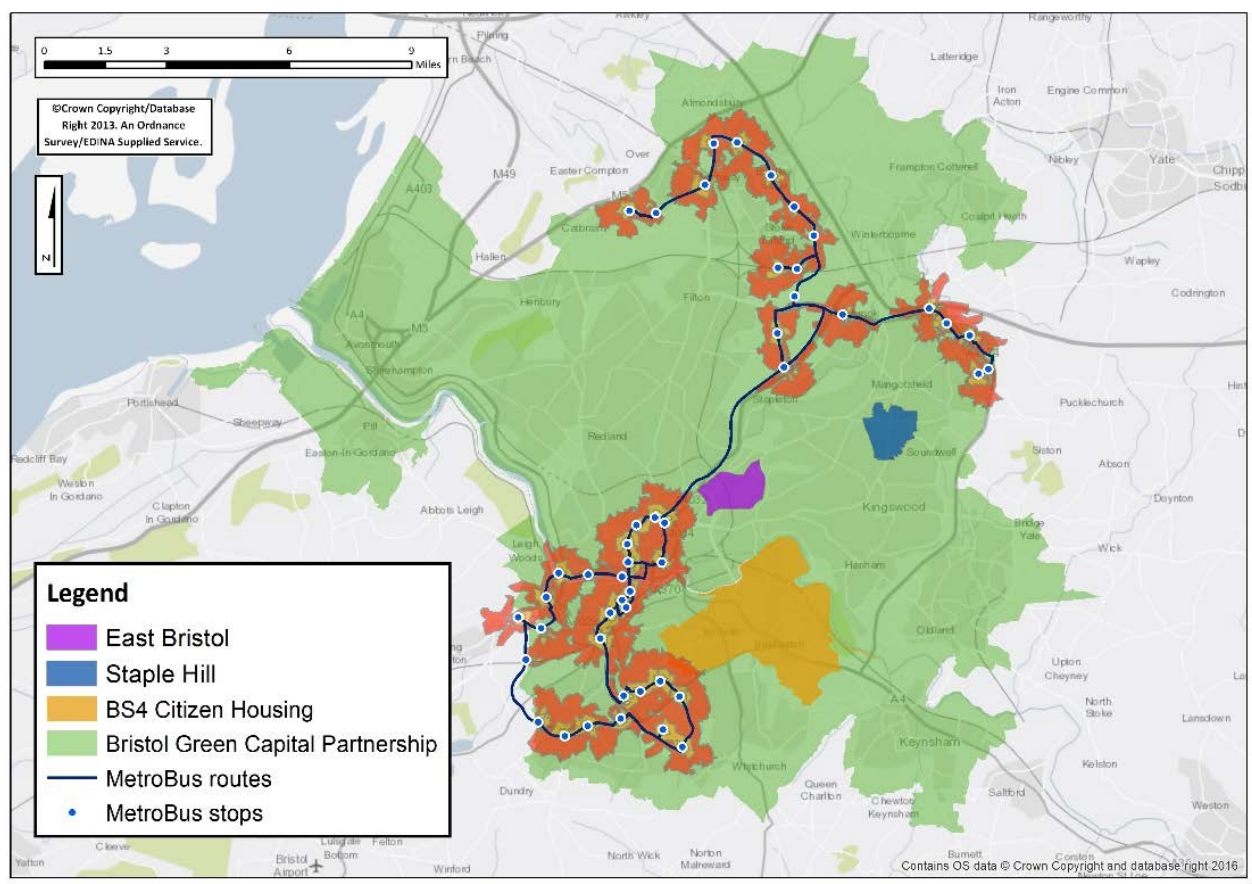

Figure 1: Map of Urban ID case study areas.

\subsubsection{Existing data}

As was identified for the carbon neutrality challenge theme, to diagnose the strategic sustainability challenges for the Bristol urban area and potential transformation pathways, data are needed which describes the current position of the city area. In order to accurately assess the scale of change needed in each of the four challenge theme areas, existing data are needed related to the main questions and issues identified for each theme. In addition, existing data for each of the five case study areas, pertinent to some of the issues raised in challenge themes are also needed. Data identification and collection is, therefore, an essential part of the Urban ID diagnostic framework.

\subsubsection{Systems/interdependency mapping}

Urban systems are complex and comprise interconnected 'systems of systems', including social 'soft' and technical 'hard' functional systems [4]. The Urban ID diagnostic framework will utilise systems thinking, and, in particular, interdependency mapping to identify the barriers to a better Bristol. Qualitative, quantitative and narrative data can all be analysed to identify interdependencies between different systems in the city and between the four challenge themes. Quantitative data can be collected by measurement and surveillance, qualitative data in focus groups, workshops, interviews and surveys and narrative data through interview and video diaries. Different methods will be used as appropriate.

\subsubsection{Co-produced/creative approaches}

For the Urban ID project to explore ways of including all people involved in decision making and problem solving, the diagnostic framework will look to improve outcomes for urban 
living through co-produced diagnoses of the problems and their causes. Creative, participatory approaches will combine and share public and academic knowledge and expertise, and change perceptions about roles people can play in shaping the future of the city. No single research method can be labelled as 'co-production'; it is a 'broad portfolio' of methods. For the Urban ID project, potential methods must be interdisciplinary and cross-sectoral, bringing diverse people together. Example methods are participatory arts, action research, co-design and investigation of 'what works'. Creative methods, such as journals and walk along semi and unstructured interviews can also be used [5], [6].

\subsubsection{Narrative interviews}

The Urban ID diagnostic framework will also utilise narrative interview and narrative inquiry in case studies. Data collected will comprise quantitative, qualitative, and narrative data elicited from individual citizens and the employees of organisations such as members of the Bristol Green Capital Partnership. The interviewing method may vary between case studies but will be open and unstructured to elicit the stories or narratives of members of different communities in the five exploratory case study areas. Presentation of the narratives interviews can be creative, participatory and artistic.

\section{BRISTOL GREEN CAPITAL PARTNERSHIP SUSTAINABILITY COMMUNITY CASE STUDY}

\subsection{The Bristol Green Capital Partnership}

The Bristol Green Capital Partnership is one of Urban ID's non-academic, partners and an independent, environmental, sustainability-focused leadership organisation operating primarily in the Bristol urban area. Its aim is to make Bristol "a sustainable city with a high quality of life for all" [9]. The partnership was founded in 2007 and formed as a Community Interest Company (CIC) in 2014. BGCP has around 800 member organisations, made up of businesses, public sector, charities and community organisations. BGCP CIC and its membership worked closely with Bristol 2015 Ltd, a company set up to facilitate activities in Bristol's year as European Green Capital in 2015. This work ensured partnership members and organisations from across the whole city played an active leadership role in the delivery of the Bristol 2015 programme. In 2016, BGCP CIC took on a new, important role, becoming a legacy organisation to ensure civic leadership for the city beyond 2015 .

\subsection{Research design}

The BGCP 'sustainability community' case study research questions and design have been developed through collaboration between researchers at the University of the West of England and BGCP CIC, with additional direction on piloting the diagnostic framework from researchers at the University of Bristol. The case study has three broad aims: to understand member organisations' visions for the partnership's future; to map membership organisations' operations and BGCP's geographic coverage; and to gather BGCP member organisations' diagnosis of the big challenges facing the city.

The research questions considered in the initial workshop were as follows:

1. How are the spatial boundaries of the BGCP community defined and where are the partnership and members active?

2. How can the Urban ID project partnership and BGCP CIC successfully engage with the diverse range of members that make up the BGCP community? 
3. How much do the four Urban ID themes resonate with BGCP members and, where they do, what are the issues in and across them?

4. In what ways can a breaking down of silos (including the "green" silo) when thinking about the BGCP community lead to advancements?

The questions will be explored with the membership through a number of different research activities, integrating the core research methods that make up the diagnostic framework. The research design will include analysis of BGCP membership data; interdependency mapping and creative/participatory approaches in workshops, an online survey; and narrative interviews to develop "partnership stories", which will feed into its $10^{\text {th }}$ anniversary events in July.

\subsection{Initial workshop}

In March 2017, the first workshop for the BGCP sustainability community case study was held. The workshop asked questions of participants related to four case study research questions. Additional questions will be explored in later stages of the case study. In total, there were eight partnership members at the workshop, two representatives of BGCP CIC and five members of the project research team, facilitating or observing events.

There were two main stages to the workshop. Firstly, a mapping exercise where BGCP members split in to two groups and discussed areas of activity of their own organisations and BGCP, and marked the locations and regions on maps. Members also discussed why they had joined BGCP, issues around the diversity of the membership, and if and why they engage with partnership events. Secondly, members completed an interdependency/systems analysis activity. One group examined the interdependencies between their organisation and the Urban ID challenge themes and the other examined the interdependencies between their organisation and the BGCP themes; energy, food, nature, resources and transport. At the end of the activity, the two groups came together, feeding back on their discussion. The mapping exercise focused on research questions 1 and 2 . Activity 2 focussed on questions 3 and 4.

\subsubsection{Activity 1: mapping exercise group 1}

"We're a member of BGCP as it's helping to represent the city in green issues, not just nationally but internationally as well".

Members defined spatial boundaries by their organisation's areas of operation at a range of scales. Two of the participants gave their immediate boundary as the Bristol urban area: GCP Chartered Architects (GCP) and Bristol Energy Network. The Avon and Somerset Constabulary (ASC) noted that their area of operation is not the same as the local authority and they view themselves as a sub-regional organisation. Friends of the Earth (FoE) are a national and global organisation, with an office in Bristol. Activities amongst the four organisations spread relatively evenly across the Bristol urban area.

In terms of the perceived boundaries of BGCP, there was a discussion around distribution of funding in the European Green Capital year from Bristol 2015 Ltd. Some communities actively involved in the partnership did not receive funding, creating animosity. The group recognised that sustainability is an issue that transcends local boundaries. There was a discussion of how BGCP could be more inclusive at the sub-regional level.

"I think environmentally too, everyone gets very excited by the idea of green cities... but of course practically speaking they do not exist in isolation and all the things we need to feed us and power us and give us water and everything else come from outside". 
4.3.2 Activity 1: mapping exercise group 2

"It's the support you get, it's being around like-minded people and it's the information that flows through it too. It's good to be a part of that".

Apart from the Bristol Civic Society (BSC) whose boundaries are historically defined as the City of Bristol, other members defined their areas of operation at a larger scale, with their main area of activity in Bristol. Imayla CIC is mainly active in Bristol, but takes children and family groups to other areas outside the city to explore nature. Collecteco, which helps organisations donate furniture, equipment and materials, is based in Bristol but goes wherever needed nationwide, excluding Scotland, and has delivered to Africa. The Schumacher Institute has a long history of research in Bristol but is active all over the world.

The group highlighted issues around diversity and inclusivity and the sustainability agenda, the need to involve younger people, and the difficulties of engaging with people who have, perhaps, bigger issues than sustainable living. The perceived area of operation of the BGCP was described as "confused" by one member, and "fluid, amoebic and variable as needed" by another. There was a perception that its boundaries have spread and it should be wider than the Bristol urban area to be a successful sustainability network, but that for some organisations a local focus stops dilution of resources.

"I think we're acutely aware of an issue around diversity..., we know we are representing a white middle class group a lot".

\subsubsection{Activity 2: interdependencies and systems analysis group 1}

The group identified interdependencies between their organisations and the four Urban ID challenge themes as well as interdependencies between the themes, marked on a grid using different coloured 'Post-Its' to record relationships (see Fig. 2).

Mobility and accessibility are vital for people getting to work and for getting staff to communities. Much of the discussion focussed on active travel, recognising issues around travelling by bike, convenience, the perceived motivations for companies encouraging active travel, and rain and hills as barriers to enthusiastic bike use. The Bristol/Bath Path was considered an important piece of infrastructure in Bristol.

Health and happiness are important aims of some of the group's organisations. Both physical and mental health are important to employee performance and attendance, and for the functioning of society, and interact with the different themes. There is a relationship between relative locations of workplaces and homes, and active travel, lunchtime walks and reducing staff turnover. Local employment hubs may offer solutions.

Inclusion and equality: For public facing organisations to be legitimate, maintaining a representative workforce is important. One organisation had created a specific strategy to collaborate with underrepresented socio-demographic groups and these collaborations had the mutual benefit of being good for their organisation's business.

Carbon neutrality: One organisation had made a commitment to reduce emissions, but there were limited ways to do this. Carbon neutral buildings require careful design and this could 'spill over' into buildings that enable healthier and happier living as well. BGCP was seen as a facilitator of links between energy use and health in the region. There are also links between the impacts of environmental issues and the health care system.

Extra themes: The group identified 'wildlife in the city and greenery' and 'food' as additional challenge themes areas. There are relationships between lack of access to green space due to limited mobility in more deprived communities and mental health. 
4.3.4 Activity 2 interdependencies and systems analysis group 2

The group identified interdependencies between their organisations and the five BGCP themes energy, food, nature, resources and transport, as well as interdependencies between the themes, recorded on a grid using different coloured post-its (see Fig. 2).

In relation to the BGCP themes:

Energy: Being unable to afford energy can lead to poor health and unhealthy people are expensive, using more resources. People are encouraged to have wood burning stoves and they are seen as green but are contributing to poorer air quality.

Food: There is a relationship between food and health that starts with breast feeding. Being able to make better lifestyle choices and better decisions leads to better health.

Nature: Parks and green spaces can be considered as resources and are under threat as local authority resources are reduced.

Transport: Congestion in the transport system has an impact on businesses but also on air quality. It badly needs to change, there needs to be a modal shift where people challenge whether they need to make a journey.

Resources: A reduction in council spending on resources means more work for BGCP organisations. Tragically, cuts will have an impact on provision of mental health and obesity programmes. As a result, the population will be unhealthier and there will be a higher cost to the NHS.

Extra themes: The group identified 'health', 'education', 'built environment' and communications/digital environment as other potential themes interlinked with sustainability. Health and education in particular were felt to cut across themes and link to everything. One group member talked of someone at their organisation who is overweight, has not had the education to eat properly so is unhealthy, and eats a lot of takeaways so is using more resources, and more energy. Reliable and fast communication systems are also essential. The digital environment is hugely important to sustainability. Inclusive sustainability was discussed, and issues around imparting information to people who cannot read or are from another country/culture, by just telling them to change.

\subsection{Outcomes}

This section provides an overview of an initial workshop with BGCP members. A more thorough analysis of themes and interdependencies will form part of the overall case study report. However, the workshop successfully provides a basis for developing activities with the wider membership, some initial feedback on BGCP and members views on the strategic sustainability challenges for a more sustainable Bristol, and provides some initial answers to the case study research questions. Though the workshop was with a fairly small sample of the BGCP membership, summaries of the group discussions show a range of topics were covered. In particular, it is interesting to note the focus on health, wellbeing and inclusive sustainability of both groups across activities 1 and 2, but particularly group 2 who were not introduced to the Urban ID challenge themes till near the end of the workshop.

The mapping exercise examined participants' views of their own organisation and the BGCP's themes in Bristol and beyond. In terms of organisations' activities, there were a range of boundaries, with some defined clearly at the Bristol City, Bristol urban area or unitary authority level and others with activities and centres all over the world. BGCP's boundaries were less clearly defined but for some members this flexibility was seen as a positive aspect of a network partnership and sustainability community. Sustainability was highlighted as an area where boundaries are relative to different organisations and sectors and a number of members felt BGCP could expand its range. 


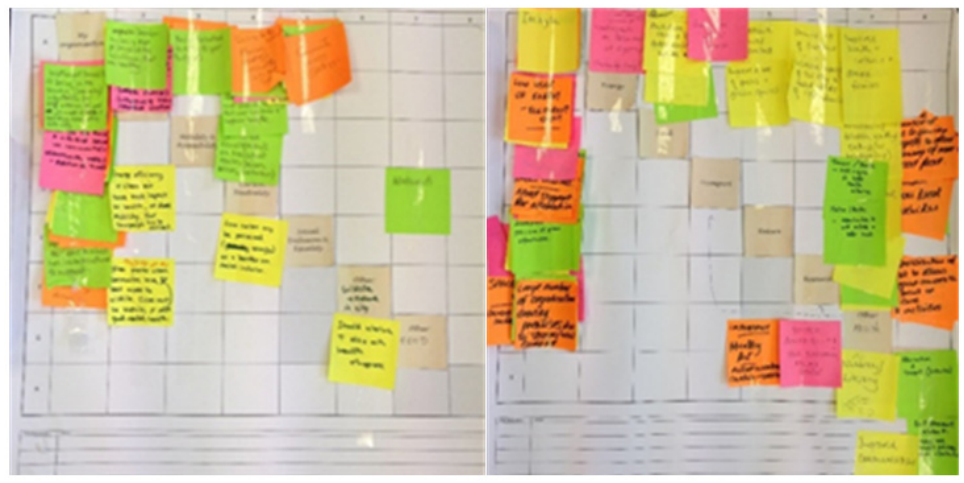

Figure 2: Photos of interdependencies/systems analysis grids for activity 2.

Activity 2 explored members' views of the Urban ID challenge themes and BGCP's themes and also looked at 'siloing' between sectors. group 1's discussions were focussed on the Urban ID themes with interdependencies identified between every theme. group 2's discussions were arguably more holistic, perhaps governed by what they saw as the "broader" themes of the BGCP. Nevertheless, all Urban ID themes were discussed, though, as noted, there was a focus on health and inclusion.

Overall, participants found it easier to talk about the interdependencies between themes rather than those with their organisations, though perhaps with more time to familiarise themselves with the activity they may have found this easier. One participant in group 1 thought that it was the interactions between Urban ID themes that were of interest, and whilst not new to sustainability experts, could be informative to other organisations. In particular, organisations might not see beyond their own direct interests, or be in a bubble, without this type of prompting to see how other organisations interact with aspects of sustainability. In group 2, one member felt the mapping exercise provided a better forum for discussion and exploring the links between different aspects of sustainability.

\section{CONCLUSIONS}

This paper has described the Urban ID project's background, development of an integrated diagnostic framework of co-produced research methods, and some initial research findings from a case study workshop with members of the Bristol Green Capital Partnership sustainability community. The initial findings of the BGCP case study highlight some interesting points. First, the boundaries of sustainability communities are not easily defined. Though there is perhaps value in expanding community boundaries so as to explore interdependencies and disrupt a siloed, BAU mindset, care has to be taken to ensure activities do not become unfocussed and cease to meet the needs of members. Second, the group activities identified the importance to participants of 'sustainability' and 'sustainability communities' being accessible and inclusive, and perhaps needing to focus on improving health and wellbeing. Though the number of participants cannot be considered representative of the wider membership, this is an important aspect to explore in subsequent activities as these are significant barriers to long-term sustainable development.

The BGCP sustainability community case study will build on this initial work to explore the views of the wider membership in more detail, in particular exploring their visions of how the Bristol urban area might become carbon neutral by 2065. As the BGCP case study 
develops, work will also continue in the other four case studies developing and piloting a set of tools that can be used to diagnose sustainability challenges. The diagnostic framework and set of core research methods allows for a thematic analysis of data collected across case studies in relation to all four challenge themes. It is envisaged that the Urban ID methodology will be replicable in different contexts to assist in developing strategies at all levels. This initial work begins to show the potential of this approach, developing a set of co-produced research methods to diagnose strategic sustainability challenges, working in partnership with a civic leadership focussed, sustainability community. Future work across the project, in different case studies with a diverse range of stakeholders will build on this initial promise.

\section{ACKNOWLEDGEMENT}

The Urban ID project is funded as part of the Urban Living Partnership by all of the UK research councils and Innovate UK, under EPSRC grant number EP/P002137/1.

\section{REFERENCES}

[1] Bristol City Council. Bristol Resilience Strategy 2016, Online. https:// www.bristol.gov.uk/documents/20182/1308373/Bristol+Resilience+Strategy/31a768fc -2e9e-4e6c-83ed-5602421bb3e3. Accessed on: 10 Apr. 2017.

[2] The Times. Sunday Times Best Place to Live Guide 2017, Online. https:// www.thetimes.co.uk/article/sunday-times-best-places-to-live-2017-3qkwjnvrm\#/. Accessed on: 10 Apr. 2017.

[3] Bristol City Council. Bristol Economic Briefing March 2017. Online. https://www.bristol.gov.uk/documents/20182/33191/Bristol+Economic+Briefing+Mar ch+2017/2e254ab5-64b3-4ba3-a0c4-e9efaff9954c. Accessed on: 10 Apr. 2017.

[4] Rosenberg, G. \& Carhart, N., A systems-based approach to creating value from infrastructure interdependencies. Proceedings of the International Symposium of Next Generation Infrastructure, pp. 453-468, 2013, http://dx.doi.org/10.14453/ isngi2013.proc.39.

[5] Campbell, H.J. \& Vanderhoven, D., Knowledge that Matters: Realising the Potential of Co-production, Online. http://www.n8research.org.uk/view/5163/Final-Report-CoProduction-2016-01-20.pdf. Accessed on: 10 Apr. 2017.

[6] Facer, K. \& Enright, B., Creating Living Knowledge, Online. https://connectedcommunities.org/wp-content/uploads/2016/04/Creating-Living-Knowledge.Final_.pdf. Accessed on: 10 Apr. 2017.

[7] Bristol City Council. Life Expectancy and Mortality By Ward. Online. https://opendata.bristol.gov.uk/Health/Life-Expectancy-And-Mortality-By-Ward/b38apgxd/data. Accessed on: 10 Apr. 2017.

[8] Office of National Statistics (ONS), 2011 Census - Built-up areas, Online. http://www.nomisweb.co.uk/articles/747.aspx. Accessed on: 10 Apr. 2017.

[9] Bristol Green Capital Partnership (BGCP) Website. Online. http://bristolgreencapital.org/. Accessed on: 10 Apr. 2017. 